\title{
Morbidity and drug prescribing patterns at a rural primary health care center of Bangladesh
}

\author{
Hasina Momtaz*, Nehlin Tomalika*, Masuda Mohsena, Mir Masudur Rhahman, \\ Niru Sultana, M Abu Sayeed \\ Department of Community Medicine, Ibrahim Medical College, Dhaka, Bangladesh \\ *Contributed equally to this study
}

\begin{abstract}
Background and objectives: World Health Organization (WHO) and the National Health Policy of Bangladesh have repeatedly been emphasizing on the use of essential drugs prescribed by generic names. The prescription monitoring studies provide a bridge between areas like rational use of drugs and evidence based medicine. Knowledge on distribution and burden of diseases in a community is essential for planning rational use of drugs in a community. The present study tried to determine the morbidity profile and drug prescribing practices of healthcare providers in a rural primary health care.

Methods: The study was conducted at a rural health center located $50 \mathrm{Km}$ north of capital city Dhaka. A semi-structured questionnaire was used for collecting data on socio-demographic conditions, clinical complaints and types of drugs prescribed. WHO prescribing indicators was used to find out the drug prescribing pattern.

Results: A total of 583 patients were enrolled. Problems related to respiratory system (21.1\%), musculoskeletal system $(17.3 \%)$ and skin diseases $(11.1 \%)$ were common reasons for visiting health centre. Oral drugs were prescribed with highest proportion (96.1\%). More than half $(62.6 \%)$ of the drugs were prescribed from essential drug list. About half $(49.1 \%)$ were antibiotics and $45.6 \%$ of the drugs were prescribed in their generic name. Anti-microbial (64.5\%), anti-peptic ulcer (43.1\%) and NSAIDs (42.5\%) were most frequently prescribed. Out of five WHO core prescription indicators, four were below the acceptable values.
\end{abstract}

Conclusion: The study demonstrated that there is an urgent need to promote rational use of drugs among the healthcare providers.

IMC J Med Sci 2018; 12(2): 50-56. EPub date: 08 March 2018

\section{Introduction}

The assessment of drug utilization is important for medical, academic and commercial purposes [1,2]. Periodic evaluations of prescriptions are essential for monitoring therapeutic efficacy, adverse effects of drugs and also for providing feedback to the prescribers [3,4]. Moreover, high cost drugs can be identified by reviewing information on drug use [5]. Currently, irrational and improper uses of drugs are major concerns worldwide [6,7]. Adverse clinical consequences and burden on limited resources are the major impact of irrational use of medicines [8]. Information on morbidity or disease profiles of a health institution is important for planning, policy formulation and decision making for best utilization of resources of health sector. In Bangladesh, there are few studies on the morbidity and related drug prescription pattern in rural primary health care facilities. Most of the available studies were conducted in tertiary care hospitals $[9,10]$. In 2015 , a study conducted in primary level rural hospital of Bangladesh reported high use of antibiotics [11]. 
Therefore, the objectives of this study were to determine the morbidity profiles of patients and to evaluate the drug prescribing practice of health care providers at a rural primary health care center near capital Dhaka using WHO recommended core prescribing indicators.

\section{Materials and Methods}

This was an observational cross sectional study. The study was conducted at Sreepur upazilla (subdistrict) health complex, a rural primary health center, located $50 \mathrm{Km}$ north of capital city Dhaka, under Sreepur upazilla of Gazipur district, Bangladesh from 16 February to 4 March 2017. The health complex was a 50-bed primary care hospital that provide both out and inpatient services. The patients attending the outpatient department and those admitted in the health center during the study period were enrolled. Patients, who were advised investigations only, came for immunization, antenatal care, follow up or referral to a different health care centers, were excluded from this study. A total of 583 patients were enrolled. A semi-structured questionnaire was used for collecting data on socio-demographic conditions, clinical complaints, presentation and types of drugs prescribed. For socio-demographic conditions, data regarding age, sex, occupation, monthly expenditure and education were collected. Questions on signs, symptoms and system involved were raised for identifying morbidity profile. To assess drug prescribing pattern, enquires were made in accordance with WHO prescribing indicators (provided below). Prescriptions were checked to find out the treatment pattern and names and types of the drugs prescribed. In case of admitted patients their case files were checked to obtain detailed disease and treatment information.

WHO recommended five core prescription indicators evaluated in this study were: (a) average number of drugs per encounter, (b) percentage of drugs prescribed by generic name, (c) percentage of encounters with an antibiotic prescribed, (d) percentage of encounters with an injection prescribed and (e) percentage of drugs prescribed from essential drugs list. Cut-off values of the indicators 2-5 were expressed as percentages [12]. Essential drugs list (EDL) of WHO was used as a framework for rational prescription of drugs [13]. The list contains drugs that are well established and already tested in practice; have established clinical use and lower cost than newer drugs. Drugs prescribed by generic name was defined when the drug(s) was mentioned in prescription by its chemical name.

Verbal consents were obtained from all adult patients and from the guardians of the children patients. All the participants were assured of their anonymity and confidentiality. After collection, data were entered, cleaned, and analyzed using the software IBM SPSS version 20. Mean, standard deviation and frequency distribution of different variables were calculated and described here.

\section{Results}

This study was conducted to assess morbidity profile and drug prescribing patterns among the patients attending a rural primary health care center in Sreepur upazilla. Analyses revealed that majority of the patients $(58.5 \%)$ were female (Table- 1$)$. Among the patients higher proportion were found to be housewives $(32.2 \%)$; whereas percentage of farmers was least $(3.6 \%)$. About one third $(36.0 \%)$ of the patients were illiterate. Table- 2 shows that most of the patients visited the health centre for problems related to respiratory system $(21.1 \%)$. Musculoskeletal system (17.3\%), skin diseases $(11.1 \%)$ and gastrointestinal involvement $(10.5 \%)$ were also common reasons for visiting the health centre.

Table-1: Socio-demographic characteristics of the study population at health complex $(n=583)$

\begin{tabular}{lc}
\hline Parameters & Number (\%) \\
\hline Gender & \\
$\quad$ Female & $341(58.5)$ \\
Male & $242(41.5)$ \\
Occupation & \\
$\quad$ Housewife & $188(32.2)$ \\
Student & $97(16.6)$ \\
Job holder & $71(12.2)$ \\
Business & $22(3.8)$ \\
Farmer & $21(3.6)$ \\
Others & $184(31.6)$ \\
Education & \\
Illiterate & $210(36.0)$ \\
Can read and Write & $248(42.5)$ \\
SSC/HSC/Equivalent & $96(16.5)$ \\
Graduate/Equivalent & $29(5.0)$ \\
\hline Note: SSC-Secondary school certificate, & HSC- Higher \\
secondary school certificate &
\end{tabular}


Table-2: Distribution of the study participants according to the system involved or diagnosis $(n=583)$

\begin{tabular}{lc}
\hline System involved & *Number (\%) \\
\hline Respiratory system & $123(21.1)$ \\
Musculoskeletal system & $101(17.3)$ \\
Skin & $65(11.1)$ \\
Gastrointestinal system & $61(10.5)$ \\
Genitourinary system & $31(5.3)$ \\
Ear nose and throat (ENT) & $29(5.0)$ \\
Eye & $15(2.6)$ \\
Dental diseases & $11(1.9)$ \\
Obstetrics problems & $11(1.9)$ \\
Non communicable disease & $8(1.4)$ \\
Surgical case & $27(4.6$ \\
Miscellaneous & $101(17.3)$ \\
\hline
\end{tabular}

Note: *Multiple response

Prescriptions of patients were studied to assess the rates of WHO indicators. The distribution of routes of administration pattern indicated that oral drugs were prescribed with highest proportion (96.1\%); next was topical $(16.1 \%)$, and then injectable $(13.6 \%)$. Majority $(62.6 \%)$ of the prescribed drugs were from essential drug list. Among the prescribed drugs nearly half $(49.1 \%)$ were antibiotics and $45.6 \%$ of all drugs were prescribed in their generic name (Table-3).

Table-3: Prescription patterns of the patients attending the health complex center $(n=583)$

\begin{tabular}{lc}
\hline Prescription pattern & $*$ Number (\%) \\
\hline Route of administration* & \\
Oral & $560(96.1)$ \\
Topical & $94(16.1)$ \\
Injectable & $79(13.6)$ \\
Per rectal & $4(0.7)$ \\
Subcutaneous & $1(0.2)$ \\
Prescribed from essential & $365(62.6)$ \\
drug list & \\
Antibiotic prescribed & $286(49.1)$ \\
Drugs prescribed in generic name & $266(45.6)$ \\
\hline
\end{tabular}

Note: *Multiple response

Table-4 shows that most frequently prescribed drugs were antimicrobial $(64.5 \%)$, followed by drugs for peptic ulcer (43.1\%), NSAIDs (42.5\%), antihistamine (40.7\%), vitamins $(39.5 \%)$ and minerals (27.6\%). Least frequently used drugs were anxiolytic (1.9\%) and antihypertensive
$(1.7 \%)$. The frequencies of commonly prescribed antimicrobials are presented in Table-5. More than one third of the prescription included azithromycin (28.7\%). Amoxicillin (11.5\%), metronidazole $(9.1 \%)$, flucloxacillin $(7.0 \%)$, ceftriaxone $(6.6 \%)$ and cefuroxime $(5.6 \%)$ were the other commonly prescribed antibiotics. The five core prescription indicators recommended by WHO were extracted from the collected data and presented in Table- 6 along with WHO recommended values. None of the five indicators could meet the WHO guideline.

Table-4: Pattern of drugs prescribed by the physicians at health center $(n=583)$

\begin{tabular}{lc}
\hline Type of drugs & *Number (\%) \\
\hline Antibiotics & $286(49.1)$ \\
Anti-parasitic, antifungal & $90(15.4)$ \\
Anti-ulcer & $251(43.1)$ \\
NSAIDs & $248(42.5)$ \\
Antihistamine & $237(40.7)$ \\
Vitamin & $230(39.5)$ \\
Minerals & $161(27.6)$ \\
Anti-emetic & $44(7.5)$ \\
Steroid & $36(6.2)$ \\
Oral Rehydration Solution & $24(4.1)$ \\
Anxiolytic & $11(1.9)$ \\
Antihypertensive & $10(1.7)$ \\
\hline
\end{tabular}

Note: *Multiple response; NSAIDs Non-steroidal Anti-inflammatory drugs

Table-5: Commonly prescribed antibiotics by the physicians at health center $(n=286)$

\begin{tabular}{lc}
\hline Name of antibiotic & $*$ Number (\%) \\
\hline Azithromycin & $82(28.7)$ \\
Amoxicillin & $33(11.5)$ \\
Metronidazole & $26(9.1)$ \\
Flucloxacillin & $20(7.0)$ \\
Ceftriaxone & $19(6.6)$ \\
Cefuroxime & $16(5.6)$ \\
Ciprofloxacin & $13(4.5)$ \\
Cotrimoxazole & $12(4.2)$ \\
Cefotaxime & $2(0.7)$ \\
Tetracycline & $2(0.7)$ \\
Doxycycline & $1(0.3)$ \\
Ceftazidime & $1(0.3)$ \\
Others & $59(20.6)$ \\
\hline
\end{tabular}

Note: *Multiple response 
Table-6: $W H O$ core prescription indicators observed at health center

\begin{tabular}{ccc}
\hline \multirow{2}{*}{$\begin{array}{c}\text { WHO prescribing } \\
\text { indicators }\end{array}$} & \multicolumn{2}{c}{$\begin{array}{c}\text { WHO core prescription } \\
\text { indicators }\end{array}$} \\
\cline { 2 - 3 } & $\begin{array}{c}\text { Study } \\
\text { value }\end{array}$ & $\begin{array}{c}\text { Optimal } \\
\text { value }\end{array}$ \\
\hline $\begin{array}{c}\text { Average number of drugs } \\
\text { per encounter }\end{array}$ & 3.31 & $\leq 3$ \\
$\begin{array}{c}\text { Drugs prescribed by } \\
\text { generic name }\end{array}$ & $45.6 \%$ & $100 \%$ \\
$\begin{array}{c}\text { Encounters with an } \\
\text { antibiotic prescribed }\end{array}$ & $49.1 \%$ & $\leq 30 \%$ \\
$\begin{array}{c}\text { Encounters with an } \\
\text { injection prescribed }\end{array}$ & $13.6 \%$ & $\leq 10 \%$ \\
$\begin{array}{c}\text { Drugs prescribed from } \\
\text { essential drugs list }\end{array}$ & $62.6 \%$ & $100 \%$ \\
\hline
\end{tabular}

\section{Discussion}

This study was an attempt to assess the morbidity profiles and the drug prescribing pattern at a primary rural health care center of Sreepur upazilla. The current study identified respiratory problems as the most prevalent health problem and it was followed by musculoskeletal problems, skin diseases and gastrointestinal disorders. The result is consistent with the findings of studies conducted at rural health center in Bangladesh and in South India [11,14]. Similar diseases are commonly encountered in outpatient department in Nepal and Nigeria $[8,15]$. Infectious diseases were the most frequently encountered diseases in this study indicating low socio-economic status of participants as infectious diseases are more prevalent among people living in poverty. Ongoing ill health is a major reason why the poor are not able to break out of the cycle of poverty and infectious diseases [16].

The results of the present study revealed that the average number of drugs prescribed per encounter was 3.3 which were not within the recommended range of WHO guideline. Similar prescribing trends were reported from earlier studies in Bangladesh and several other developing countries $[9,10,17]$. However, practice of prescribing drugs within the WHO recommended range $(\leq 3)$ was observed in Zimbabwe, Jordan, Brazil, India and Nepal [1822]. Practice of poly-pharmacy might be linked to financial incentives from the pharmaceuticals or local pharmacies or lack of therapeutic training of prescribers. It is well known that poly-pharmacy may lead to adverse drug reactions, increase risk of drug interactions, dispensing errors, decrease adherence to drug regimens and unnecessary expenses. This reflects the need to strengthen the habit of rational prescribing of drugs by medical practitioners.

WHO strongly recommends prescribing medications by generic name as a safety precaution for patients because it identifies the drug clearly, enables better information exchange and allows better communication between health care providers [23]. About $45.6 \%$ of drugs in this study were prescribed by generic name which was far less than WHO recommended guideline of $100 \%$. A previous study conducted at a tertiary care hospital of Bangladesh reported the rate of prescription of drugs by generic name around $50 \%$, while another study at a Government referral hospital in northern Bangladesh found no prescription by generic name $[9,10]$, The rate of prescribing drugs in generic name ranges from $27 \%$ to $61 \%$ in other developing countries of Asia and Africa [10,24-27].

High rate $(39 \%-62 \%)$ of antibiotic prescription was reported from many developing countries of Asia, Africa and Middle East [18,28-30]. In the present study, about $50 \%$ of the prescription contained antibiotics; when according to WHO 15\%-25\% prescriptions with antibiotics are expected in developing countries where infectious diseases are prevalent [31]. High prevalence of infectious diseases in developing countries compared to developed countries might be a reason for frequent prescription of antibiotics. However, irrational prescribing of antibiotics was observed even in hospitals of developed countries [32]. Such practice may lead to increased risk of adverse reaction, hospital admission and emergence of antibiotic resistant bacteria [33,34].

In this study, the rate of prescribed parenterally administered drugs (13.6\%) was found higher than the acceptable range of WHO guideline. Previous studies in tertiary care hospitals of Bangladesh reported this rate as $17.2 \%$ and $6.7 \%[9,10]$. The rate was even higher in tertiary health care facilities in countries like Nigeria (26.9\%-40.6\%) and Ethiopia (38.1\%) [35-37]. Use of injectable form of drugs was higher in tertiary health care facilities because in those hospitals patients with serious conditions were treated. Use of injections 
instead of oral formulations increases the costs of therapy and the risk of blood-borne diseases such as hepatitis and HIV.

In this study, the percentage of drugs prescribed from the national EDL was found to be $62.6 \%$, which was very low in comparison with the rates observed in different parts of the world. The study conducted in different countries revealed that drug prescribed from EDL were $99 \%$ in Ethiopia [38], 96.8\% in Saudi Arabia [12] and $96.1 \%$ in Nigeria [15]. Generally, in other developing countries values higher than $80 \%$ had been observed [39]. One of the possible reasons for this lower rate could be the lack of prescribers understanding on the importance of essential drug concept. Other reason could be that most of the prescriptions included NSAIDs, anti-ulcerants, multivitamins and multi-minerals, which are not enlisted in EDL of Bangladesh.

The current study had some limitations. The mean cost of drugs and mean consultation time were not calculated. The diagnoses of diseases were based upon clinical symptoms and the investigation reports were not available in most cases. The study had further limitation that it was not designed to reveal the reasons leading to irrational prescription of drugs. The current study recommends that clinicians should be made aware about the WHO guidelines for rational prescription of drugs.

\section{Acknowledgments}

We acknowledge the active cooperation of $3^{\text {rd }}$ year students (Batch IM-14) of IMC. We are thankful to the UHFPO of Sreepur upazilla health complex and his staff for their full support. We are also grateful to all participants who volunteered the study.

\section{Contribution of authors}

HM and NT: Data analysis and manuscript writing; MM: Concept, data analysis and manuscript editing; NS: Preliminary concept; MMR: Supervision of field work and data collection; MAS: Overall supervision

\section{Competing interest}

None

\section{Funding}

Ibrahim Medical College

\section{References}

1. World Health Organization. Introduction to drug utilization research. Oslo: World Health Organization. 2003; 49 p.

2. Uppal R, Nayak P, Sharma PL. Prescribing trends in internal medicine. Int $J$ Clin Pharmcol Ther Toxicol. 1984; 22(7): 373-376.

3. Krishnaswamy K, Kumar BD, Radhaiah G. A drug use survey- precepts and practice. Eur $J$ Clin Pharmacol. 1985; 29(3): 363-370.

4. Pradhan SC, Shewade DG, Shashindran CH, Bapna JS. Drug utilization studies. National Med J India. 1988; 1(4): 185-189.

5. Marshner JP, Thürmann $\mathrm{P}$, Harder $\mathrm{S}$, Rietbrock N. Drug utilization review on a surgical intensive care unit. Int $J$ Clin Pharmacol Ther. 1994; 32(9): 447-451.

6. Hogerzeil HV. Promoting rational prescribing: an international perspective. $\mathrm{Br} J$ Clin Pharmacol. 1995; 39: 1-6.

7. Yadav AK, Bhandari R, Rai B, Giri S, Baral DD, Mandal M. Presentation, prescription pattern and time taken to discharge from an emergency department of eastern Nepal. Health Renaissance. 2014; 12(3): 209-214.

8. Lamichhane DC, Giri BR, Pathak OK, Panta OB, Shankar PR. Morbidity profile and prescribing patterns among outpatients in a teaching hospital in Western Nepal. Mcgill J Med. 2006; 9(2): 126-133.

9. Afsan M, Alam MM, Noor N, Ahmed AHH. Prescribing practices in the outpatient department in a tertiary care teaching hospital in Bangladesh. Update Dent Coll J. 2012; 2(2): 13-17.

10. Sultana F, Rahman A, Paul TR, Sarwar MS, Islam MAU, Rashid M. Prescribing pattern and prescription errors: A study at a tertiary care hospital of Bangladesh. Bangladesh Pharm J. 2015; 18(1): 20-24.

11. Ahmed AA, Jilani MSA, Chowdhiry OA, Islam KMS, Hossain MA, Alam MJ, et al. Use of antibiotics in selected tertiary and primary level health care centers of Bangladesh. Ibrahim Med Coll J. 2015; 9(2): 42-44. 
12. World Health Organization. How to investigate drug use in health facility: selected drug use indicators. Geneva: World Health Organization; 1993. EDM research series no. 007.

13. World Health Organization. The use of essential drugs. Seventh report of WHO expert committee (including the revised model list of essential drugs). Geneva: World Health Organization; 1997. 74 p Report No.:867.

14. Gupta A, Chellaiyan V, Lohiya A, Suliankatchi RA, Upadhayay R, Palanivel C. Morbidity profile of out-patients attending a primary health centre in rural Puducherry, South India. Natl J Community Med. 2014; 5(4): 424-427.

15. Jimoh AO, Omar I, Adebisi IM, Sani Z, Bello A, Abubakar SB, et al. Review of morbidity profiles and drug prescribing patterns of a university clinic in North-Western Nigeria. Int Inv J Med Med Sci. 2014; 1(8): 107-115.

16. World Health Organization. Scaling up the response to infectious diseases - A way out of poverty. Geneva: World Health Organization. 2002; 101p Report No.: WHO/CDS/2002.7.

17. Hogerzeil HV, Bimo, Ross-Degnan D, Lang RO, Ofori-Adjei D, Santoso B, et al. Field tests for rational drug use in twelve developing countries. Lancet. 1993; 342(8884): 1408-1410.

18. Trap B, Chinyanganya FW, Hogerzeil HV, Nathoo KJ, Chidarikire A, Moore H. How to improve management of an essential drugs programme by regular surveys. Zimbabwe Essential Drugs Action Programme (ZEDAP), Ministry of Health and Child Welfare Directorate of Pharmacy. 1995; 113 p.

19. Otoom S, Batieha A, Hadidi H, Hasan M, AlSaudi K. Evaluation of drug use in Jordan using WHO prescribing indicators. East Mediterr Health J. 2002; 8(4-5): 537-543.

20. Acurcio FA, Perini E, Magalhaes SM, Terceiro LG, Vieira Filho JM, Coutinho KE, et al. Analysis of medical prescriptions dispensed at health centers in Belo Horizonte, Minas Gerais, Brazil. Cad. Saúde Pública. 2004; 20(1): 72-79.

21. Mhetre NA, Bodhankar SL, Pandit VA, Zambare GN. Study of pattern of drug usage in an urban area. Indian J Pharmacol. 2003; 35: 316-317.

22. Alam K, Mishra P, Prabhu M, Shankar PR, Palaian S, Bhandari RB, et al. A study on rational drug prescribing and dispensing in outpatients in a tertiary care teaching hospital of Western Nepal. Kathmandu Univ Med J. 2006; 4(4): 436-443.

23. World Health Organization. Guidelines on the use of international nonproprietary names (INNs) for pharmaceutical substances. Geneva: World Health Organization. 1997; 41 p.

24. Akande TM, Ologe MO. Prescription pattern at a secondary health care facility in llorin, Nigeria. Ann Afr Med. 2007; 6(4): 186-189.

25. Enato EFO, Sounyo AA, Madadi P. Assessment of disease profiles and drug prescribing patterns of health care facilities in Edo state, Nigeria. $J$ Public Health Afr. 2012; 3(25): 101-106.

26. Shankar PR, Partha P, Nagesh S. Prescribing patterns in medical outpatients. Int $J$ Clin Pract. 2002; 56(7): 549-551.

27. Sarkar C, Das B. Prescribing trends in a teaching hospital in western Nepal. $J$ Nepalgunj Med Coll. 2002; 2: 4-7.

28. Karande S, Sankhe P, Kulkarni M. Patterns of prescription and drug dispensing. Indian $J$ Pediatre. 2005; 72: 117-121.

29. Sharif SI, Al-Shaqra M, Hajjar H, Shamout A, Wess L. Patterns of drug prescribing in a hospital in Dubai, United Arab Emirates. Libyan J Med. 2008; 3(1): 10-12.

30. Moghadamnia AA, Mirbolooki MR, Aghili MB. General practitioner prescribing patterns in Babol city, Islamic Republic of Iran. East Mediterr Health J. 2002; 8(4/5): 550-555.

31. International Network for Rational Use of drugs and World Health Organization. How to investigate drug use in health facilities: selected drug use indicators. Geneva: World Health Organization; 1993. Research Series No.7.

32. Meesters K, Mauel R, Dhont E, Walle JV, De Bruyne P. Systemic fluoroquinolone prescriptions for hospitalized children in Belgium, results of a multicenter retrospective 
drug utilization study. BMC Infect Dis. 2018; 18: 89. doi.org/10.1186/s12879-018-2994-z.

33. Wiffen P, Gill M, Edwards J, Moore A. Adverse drug reactions in hospital patients: a systematic review of the prospective and retrospective studies. Bandolier Extra. 2002; 1-14.

34. World Health Organization. Containing antimicrobial resistance. Geneva: WHO Policy Perspectives on Medicines, 2005.

35. Ibrahim MTO. Physicians prescribing behavior in two tertiary health care facilities in north western Nigeria, Analysis of 518 prescriptions. Sahel Med J. 2004; 7(4): 115-118.

36. Aghaji MN. Injection practices in Enugu Nigeria. Jnl College of Medicine. 2002; 7(2): 118-120.
37. Desalegn AA. Assessment of drug use pattern using WHO prescribing indicators at Hawassa University teaching and referral hospital, south Ethiopia: a cross-sectional study. BMC Health Serv Res. 2013; 13: 170.

38. Ethiopia Ministry of Health, World Health Organization. Assessment of the pharmaceutical sector in Ethiopia. Addis Ababa, Ethiopia: World Health Organization; 2003. 40p.

39. Hogerzeil HV, Walker GJ, Sallami AO, Fernando G. Impact of an essential drugs program on availability and rational use of drugs. Lancet. 1989; 1(8630): 141-142. 